\title{
TBI and Concussions in Student Athletes: How do Severity of Injury, Age, and Gender Influence Recovery
}

\author{
Margaret Semrud-Clikeman $^{1} \cdot$ Katherine M. Klipfel $^{1}$
}

Received: 12 June 2015 /Revised: 6 October 2015 / Accepted: 8 October 2015 / Published online: 21 October 2015

(C) American Academy of Pediatric Neuropsychology 2015

\begin{abstract}
Concussions and mild traumatic brain injuries are seen in increasing numbers of children and adolescents participating in sports as well as in playground activities. This review evaluated literature in the past 20 years studying gender, age, and neuropsychological effects of concussions and traumatic brain injuries. Studies have found differences in age and possibly gender among neuropsychological effects, emotional adjustment, and recovery. Females appear to be susceptible to visual memory and internalizing difficulties following recovery. Males have been found to have difficulty with externalizing behavior in some studies. Other studies have not found gender differences but have found age differences in the expression of depression and/or anxiety. In addition, several studies have demonstrated long-term difficulties in the areas of memory and internalizing behaviors suggesting that serial evaluations for complicated concussions and TBI are warranted. Based on the empirical evidence, suggestions for reintegration into school and for school reentry programming are provided.
\end{abstract}

Keywords Concussion - Traumatic brain injury · Gender . School reentry

Approximately 823 per 100,000 individuals sustained a traumatic brain injury (TBI) that resulted in emergency department visit in 2010 (CDC 2014a), with $17 \%$ of these being due to concussions (Conn et al. 2003). Of these injuries, $70.3 \%$ are reported for children between the ages of 10 and

Margaret Semrud-Clikeman semru002@umn.edu

1 University of Minnesota Medical School, Box 486 Mayo, Minneapolis, MN 55455, USA
19, with $20.8 \%$ occurring while playing football and soccer (Sieger et al. 2015). These rates increased across the previous decade, with children and adolescents among the most likely to visit emergency departments (CDC 2014b). It has also been estimated that $16 \%$ of these children who experience a severe TBI will have a permanent disability which results in significant impairment throughout the lifespan (Armstrong et al. 2008). The top US sports and activities resulting in head injury/concussions are cycling, football, baseball/softball, skateboards/scooters, and winter sports (US Consumer Product Safety Commission 2007).

The extant literature on concussions is just beginning to explore the neuropsychological and emotional aspects of this disorder. Much of the research is with children and adolescents with TBI, which is a related disorder. The purpose of this article is to explore the extent to which concussions and mild TBI differ between the genders as well as by age. At times, it is necessary to utilize the literature on mild TBI to investigate this area, but the emphasis of this chapter is on concussions.

Concussion is a mild TBI that occurs within a sports context and generally involves confusion, disorientation, and sometimes amnesia (Webb and Salinas 2011). Because approximately $63 \%$ of boys and $73 \%$ of girls engaged in some type of sport and playground activities, it is not surprising that over 300,000 athletes per year are involved in sports-related head injuries (Webb and Salinas 2011). It is important to recognize that these reported concussions are based on athletes that lost consciousness; which is about $10 \%$ of the concussions. Another study found that only $23 \%$ of football players and $20 \%$ of soccer players recognized that they had experienced the concussion which was later diagnosed (Delaney et al. 2002).

The average recovery time for concussions may be, for some athletes, as little as 1 week to a protracted course extending for weeks or even months (Sieger et al. 2015). At 
times, difficulty will not be noted until the athlete returns to school particularly when there are attentional and fatigue difficulties (Lovell et al. 2004). A delay in diagnosis of a concussion frequently means that the child/adolescent returns to play and is more susceptible to a second injury or what is termed a second-impact syndrome.

It is sobering to note that the rate of reinjury in athletes is higher for those who have already experienced a concussion. Studies have found that athletes are four to six times more likely to experience a second concussion, and that the second concussion results from milder trauma (Guskiewicz et al. 2003). When an athlete has experienced more than three concussions, it has been found that more severe symptoms are found with each consecutive concussive injury (Collins et al. 2002). A minority of athletes experiencing a concussion may go on to experience second impact syndrome (SIS). This is a fairly rare syndrome that is found in athletes 21 and younger where rapid brain swelling occurs after a second impact to the brain and has been linked to changes in brain metabolism following a concussion (Giza and Hovda 2001)

There are many aspects in studying concussions and mild TBI that are important to recognize. Specifically, level of injury, age, and gender are important variables to consider. The Glasgow Coma Scale (GCS) is used to assess severity (Jennett and Teasdale 1981). This scale evaluates the child's level of consciousness and response. It assesses eye opening (1-4 points with 4 points for spontaneous and 1 for no response), motor responses (1-6 points with 6 points for follows commands to 1 point for no response), and verbal (1-5 points with 5 points for oriented and 1 point for no response) (for a full discussion, see Semrud-Clikeman 2001). The lower the score, the more severe the head injury. The GCS has been used extensively with adults but is less useful for young, preverbal children. The Children's Coma Scale (CCS) is designed for children under the age of 3 (Henry et al. 1992). This scale does evaluate eye movements and nonverbal signs (crying and breathing rate) rather than talking and basic motor movements (flexion and extension) rather than following commands. One of the difficulties with the GCS and the CCS is the lack of validation of these measures with children.

Another measure is the length of post-traumatic amnesia (PTA). PTA is the time required for a child to understand time and spatial orientation as well as recalling prior events. The length of PTA has been found to correlate with severe injury. A PTA of more than a week shows the most impairment following recovery (Ewing-Cobbs et al. 2004). Similar to problems noted with the GCS and CCS there is a lack of validation of length of PTA beyond a few studies. A few studies have found that PTA and loss of consciousness were not associated with post-concussion symptom reporting (Lau et al. 2011; Meehan et al. 2013; Merritt et al. 2015). Others have found that these variables are predictive of post-concussion symptoms reporting and prolonged recovery (Collins et al. 2003;
McCrea et al. 2013). While a few studies have found that loss of consciousness (LOC) and PTA are predictive, most studies have not. The question has been raised whether our current tools are sensitive enough to really determine the extent of symptoms and outcomes with more research needed into neuroimaging techniques, blood proteins, and other areas of investigation to properly understand the recovery from concussions (Merritt et al. 2015)

Level of Injury Head injuries are open or closed in nature. An open head injury is one that involves a wound caused by an object penetrating the skull and entering the brain. These are rare in children and adolescents. We will be discussing closed head injury. A closed head injury is one when the head strikes a hard surface, a hard surface hits the head (i.e., a bat), or if a baby is shaken causing early child abuse. Generally, closed head injuries are diffused (widespread), have focal damage in a specific region of the brain, or have a combination of the two. In diffuse injury, the impact is due to shearing of white or gray matter and is most often the result of car accidents or falls. Shearing is when the long mylineated axons are stretched to the point of breaking off or becoming misshapen. When the head hits something stationary or is hit by something, there is a reciprocal movement at the point of impact as well as away. So, there may be two or more areas that are damaged with one at the impact and one on the opposite side of the impact. This acceleration and deceleration accounts for difficulties that are present in areas beyond the area of impact. The area most susceptible to injury is the frontal lobes and the anterior portion of the temporal poles. This is also true for concussions.

Injuries are generally grouped into mild, moderate, and severe classifications, with severe injuries showing the most damage and the longest recovery time. Mild and moderate injuries associated with TBI, as well as concussions, generally resolve within 14 to 180 days. Approximately 50 to $75 \%$ of head injuries are in the mild category and generally also include concussions (Hale et al. 2015).

Mild head injuries and concussions generally do not involve a loss of consciousness. In addition, there is often transient but immediate impairment of thinking skills and awareness that generally resolves in the next few days. Simple concussions are those that generally resolve within 7 to 10 days with complex concussions taking longer and possibly extending into years. Current studies strongly suggest that neuropsychological assessments be conducted to determine what, if any, deficits there are present, as well as whether these difficulties continue over time (Shuttleworth-Edwards 2008). Moderate head injuries include a loss of consciousness for 1 to $24 \mathrm{~h}$. Severe head injuries are those with a loss of consciousness for more than $24 \mathrm{~h}$ and a coma scale in the severe range. Often, attention and memory are affected, as well as an increase in psychiatric disorders, in both moderate and severe head injuries (Tonks et al. 2007). 
Age Effects The timing of when an injury occurs is closely related to what long-term effects may be present. Younger children generally sustain injury due to car accidents or child abuse. Children ages 4 to 11 generally are victims of pedestrian or bike accidents, while teenagers are most susceptible to car accidents. Younger children may show difficulty with learning, and an early age is generally associated with more significant cognitive deficits (Morgan et al. 2003). The developing brain is more vulnerable to damage due to the rapid growth spurts seen in the first 3 years of life. The most common structures affected in a concussion are in the frontal lobe and in the temporal poles and temporal lobe structures (hippocampus, amygdala). Disruption of neural pathways at this age is particularly problematic as key structures, such as the hippocampus and temporal lobe, are disrupted and thus new learning and language is affected.

Age may play a role in what symptoms are reported as most significant by parents. Preschool children generally do not report symptoms, and parent report is most commonly relied upon. A study comparing preschool and school-aged children who have suffered a concussion/mild TBI found that children older than 5 years of age were reported to have more symptoms than younger children (McKinlay et al. 2014). Children 5 years and younger were reported to show difficulties with loss of consciousness, fatigue, vomiting, feeling sick, and headaches. Children above 5 years of age showed all of these symptoms plus problems with memory, anxiety, and dizziness.

Early damage to the frontal lobes may not be obvious until years following the injury when executive functions are expected to develop (Baron 2008). Self-monitoring of behavior, impulse control, inhibition, and insight into behavior generally develop during adolescence and are particularly susceptible to damage from TBI or concussions. It is also important to note that injury rates decrease for females during the first 15 years of life, while the incidence for males increases between 5 and 15. Sports activities, such as football, soccer, and lacrosse, increase the rates of concussions and TBI for both genders in adolescence.

Additional studies have found that high school athletes report longer times for recovery from symptoms compared to college athletes; 15 days for high school athletes and 6 days of collegiate athletes (Williams et al. 2015). In contrast, college and high school athletes showed cognitive recovery at similar rates of 5 and 7 days, respectively. The authors interpret these difficulties as related to younger brains experiencing more difficulty with impaired neurotransmission and plasticity with unmyelinated axons being more vulnerable to insult (Fineman et al. 2000; Reeves et al. 2005).

Gender Effects Gender effects have not been as well studied as age and region of injury. Table 1 summarizes recent studies of children and adolescents who have experienced head injuries and concussions, with focus on internalizing symptoms. Most studies have combined females and males with fewer studies looking expressly at females. Participation by girls in sports has increased greatly in recent years with estimates of 47 to $60 \%$ of females participating in sports (Giza and Hovda 2001). Some have found that collegiate females have more concussions when playing soccer and basketball compared to males (Agel et al. 2007; Dick et al. 2007). Neuropsychological weaknesses are more pronounced in females on measures of reaction time with more post-concussion symptoms reported (Broshek et al. 2012). Moreover, it was found that females were 1.7 times more likely to experience cognitive impairment following a concussion compared to males (Broshek et al. 2005). A suggestion has been made that females are at higher risk due to weaker musculoskeletal support for the head, more perfusion cerebrally, and higher rates of glucose metabolism and circulating levels of estrogen and progesterone (Webb and Salinas 2011).

While there is a very sparse literature for collegiate female athletes, there is an even sparser literature that looks at gender differences in childhood and adolescent concussion. Table 1 indicates that out of the 31 studies examined, $42 \%$ of the studies did not examine gender effects. Two reviews of gender effects (Dick 2009; Toledo et al. 2012) found that females tend to have more headaches following a concussion independent of age and tend to show a poorer outcome, particularly following a sports-related injury. A further meta-analysis found that females show more symptoms than males do particularly with post-concussive symptoms, poorer memory, more irritability, and anxiety and depression (Farace and Alves 2000). In addition, one review reported that females showed more significant declines in baseline testing, poorer reaction times, and more self-reported symptoms than males do (Grady 2010).

While there is some conflicting evidence that females show a different trajectory for recovery compared to males (see Table 1), there is research suggesting that females show more difficulty with simple and complex reaction time (Broshek et al. 2005; Colvin et al. 2009), visual memory (Covassin et al. 2007), executive functioning (Schmidt et al. 2012), dizziness, fatigue, and poorer concentration (Broshek et al. 2012; Grady 2010), headaches (Hoffman et al. 2011), and internalizing symptoms by mother report (Peterson et al. 2013). An additional study found that females showed almost twice as great a decline in cognitive functioning compared to males (Broshek et al. 2012; Broshek et al. 2005). It has been suggested that the effect of concussion on preadolescent girls is an area that is in great need of further study particularly as girls' brains appear to mature up to 2 years earlier than boys do (Lenroot et al. 2007).

Some studies did find males performing more poorly than females on specific tasks and behaviors. As Table 1 illustrates, there were a few studies that found males to be more affected than females. Males were found to show higher rates of 
Table 1 Summary of studies of TBI and concussions in children, adolescents, and college-age athletes

\begin{tabular}{|c|c|c|c|}
\hline Author & Gender & Age & Conclusion \\
\hline Allen et al. (2010) & $\begin{array}{l}300 \text { children (150 TBI and } 150 \\
\text { matched nonbrain-injured controls). } \\
\text { The TBI sample was } 52.1 \% \text { male. }\end{array}$ & $\begin{array}{l}\text { Mean age }=11.7 \text {, range } \\
\text { 5-19 years }\end{array}$ & $\begin{array}{l}\text { TBI group performed more poorly across all } \\
\text { subscale and index measures of memory and } \\
\text { attention. Gender was not explored. }\end{array}$ \\
\hline $\begin{array}{l}\text { Bloom, Levin, and } \\
\text { Ewing-Cobbs } \\
\text { (2001) }\end{array}$ & 46 children ( 29 males, 17 females) & $\begin{array}{l}6-15 \text { years at the time of } \\
\text { injury, assessed at least } \\
1 \text { year post-injury }\end{array}$ & $\begin{array}{l}\text { ADHD and depressive disorder were among the most } \\
\text { common lifetime and new onset diagnoses. } \\
\text { Externalizing behaviors were more likely to persist, } \\
\text { as compared to internalizing behaviors. Gender not } \\
\text { explored. }\end{array}$ \\
\hline Broshek et al. (2005) & $\begin{array}{l}131 \text { male }(n=94) \text { and female }(n=37) \\
\text { high school and collegiate athletes } \\
\text { who had sustained a sports-related } \\
\text { concussion }\end{array}$ & $\begin{array}{l}\text { High school }(47.3 \%) \\
\text { and college }(52.7 \%) \\
\text { athletes }\end{array}$ & $\begin{array}{l}\text { Females showed greater declines from baseline than } \\
\text { males in simple and complex reaction times at the } \\
\text { time of initial evaluation after injury. They also } \\
\text { showed more post-concussion symptoms (e.g., } \\
\text { fatigue, lightheadedness, seeing flyspecks, difficulties } \\
\text { concentrating) than males. Females were cognitively } \\
\text { impaired at a rate of } 1.7 \text { times than that of males } \\
\text { following sports-related concussion. }\end{array}$ \\
\hline $\begin{array}{l}\text { Chrisman and } \\
\text { Richardson } \\
\text { (2014) }\end{array}$ & $\begin{array}{l}36,060 \text { participants }(\text { Males }=50.8 \% \\
\text { of the sample) }\end{array}$ & $\begin{array}{l}\text { 12-17 years with } \\
\text { previous concussions }\end{array}$ & $\begin{array}{l}\text { Past concussion was associated with more than 3- } \\
\text { fold risk for depression. While gender was not } \\
\text { related to outcomes of depression, parental } \\
\text { mental health and older age increased risk for } \\
\text { depression. Higher income was protective. }\end{array}$ \\
\hline $\begin{array}{l}\text { Colvin et al. } \\
\qquad(2009)\end{array}$ & $\begin{array}{l}N=234 \text { soccer players ( } 141 \text { females, } \\
\quad 93 \text { males })\end{array}$ & Ages 8-24 years & $\begin{array}{l}\text { History of concussion was associated with worse } \\
\text { performance on ImPACT testing than those } \\
\text { without history of concussion. Females } \\
\text { performed more poorly and reported more } \\
\text { symptoms than males did. }\end{array}$ \\
\hline $\begin{array}{l}\text { Corwin et al. } \\
\qquad(2014)\end{array}$ & $\begin{array}{l}247 \text { children and adolescents who were } \\
\text { presented to a sports medicine clinic } \\
\text { for concussion ( } 58 \% \text { male) }\end{array}$ & $7-18$ years & $\begin{array}{l}73 \% \text { of children experienced symptoms for longer } \\
\text { than } 4 \text { weeks. } 73 \% \text { of children required school } \\
\text { accommodations, and } 61 \% \text { of children } \\
\text { experienced decline in grades. Several symptoms } \\
\text { were associated with prolonged recovery (e.g., } \\
\text { history of depression, history of anxiety, } \\
\text { dizziness, oculomotor abnormalities, and prior } \\
\text { concussions). Gender not studied. }\end{array}$ \\
\hline $\begin{array}{l}\text { Covassin et al. } \\
\text { (2007) }\end{array}$ & $\begin{array}{l}79 \text { college athletes } \\
\text { ( } 41 \text { males, } 38 \text { women) }\end{array}$ & College athletes & $\begin{array}{l}\text { While males and females did not differ on preseason } \\
\text { ImPACT testing, cognitive and post-concussive } \\
\text { symptoms differed after concussion. Females } \\
\text { performed more poorly than males did on tasks of } \\
\text { visual memory. Men were more likely to report } \\
\text { vomiting and sadness than females. }\end{array}$ \\
\hline $\begin{array}{l}\text { Frommer, Gurka, } \\
\text { Comstock, and } \\
\text { Saliba, (2011) }\end{array}$ & $\begin{array}{l}391 \text { concussion ( } 283 \text { males, } 108 \text { females) } \\
\text { in year } 1 \text { of study, and } 421 \text { concussions, } \\
327 \text { males, } 94 \text { females) in year } \\
2 \text { of study }\end{array}$ & $\begin{array}{l}\text { High school students } \\
\qquad(\text { mean age }=15.9 \text { years })\end{array}$ & $\begin{array}{l}\text { During year 1, results showed that males displayed } \\
\text { greater symptoms of amnesia and confusion/ } \\
\text { disorientation after concussion. In year } 2 \text { of study, } \\
\text { males reported more amnesia and confusion/ } \\
\text { disorientation than females did, though females } \\
\text { reported greater drowsiness after concussion than } \\
\text { males did. The number of concussion symptoms } \\
\text { did not significantly differ among males and } \\
\text { females. Females and males were also similar in } \\
\text { their time to return-to-play and symptom resolution. }\end{array}$ \\
\hline $\begin{array}{l}\text { Geraldina et al. } \\
\quad(2003)\end{array}$ & 96 participants & $\begin{array}{l}0-18 \text { years(subdivided into } \\
0-6,7-13,14-18 \text { years) }\end{array}$ & $\begin{array}{l}\text { Younger patients showed greater internalizing } \\
\text { behaviors, while older children showed greater } \\
\text { behavior problems. GCS scores, neurological } \\
\text { impairment, and male gender were most } \\
\text { predictive of poor psychological, behavioral, } \\
\text { and adjustment outcomes. }\end{array}$ \\
\hline $\begin{array}{l}\text { Hoffman et al. } \\
\qquad(2011)\end{array}$ & $\begin{array}{l}452 \text { individuals recruited through } \\
\text { inpatient rehabilitation services } \\
(\text { males }=71 \%)\end{array}$ & $\begin{array}{l}16 \text { years of age and older } \\
(\text { mean age }=43.7, S D=19.7)\end{array}$ & $\begin{array}{l}71 \% \text { of participants report headache within the first } \\
\text { year of injury. Headaches were not related to TBI } \\
\text { severity. History of headache and female status } \\
\text { predicted more headaches. }\end{array}$ \\
\hline $\begin{array}{l}\text { Kirkwood et al. } \\
\qquad(2000)\end{array}$ & $\begin{array}{l}38 \text { children with severe TBI ( } 82 \% \text { male }) \text {, } \\
51 \text { with moderate TBI ( } 71 \% \text { male }) \text {, } \\
\text { and } 55 \text { with orthopedic injury (OI) } \\
(62 \% \text { male })\end{array}$ & $6-12$ years of age at injury & $\begin{array}{l}\text { Children who sustain TBIs are at increased risk for } \\
\text { depression as compared to orthopedic injury. } \\
\text { Gender was not investigated. }\end{array}$ \\
\hline $\begin{array}{l}\text { Kontos et al. } \\
\quad(2012)\end{array}$ & & High school, college & $\begin{array}{c}\text { Athletes with concussion showed greater levels of } \\
\text { depression from baseline at } 2,7 \text {, and } 14 \text { days }\end{array}$ \\
\hline
\end{tabular}


Table 1 (continued)

\begin{tabular}{l} 
Author \\
\hline $\begin{array}{c}75 \text { athletes }(40 \text { high school males, } \\
14 \text { high school females, } 11 \text { college } \\
\text { males, and } 10 \text { college females })\end{array}$
\end{tabular}

Kurowski et al. (2013)

132 patients( $65.2 \%$ males $)$

Luis and Mittenberg, (2002)

\section{Massagli et al.} (2004)

Max et al. (2011)

Max et al. (2012)

Max et al. (1998)

24 children per condition (75\% males)

177 participants (71\% males), with mild, moderate, and severe TBI

77 participants (71 \% males), with mild, moderate, and severe TBI

990 children with mild TBI and 1470 controls

Max et al. (2006)
177 children and adolescents who sustained moderate to severe TBI (71\% males)
Children aged $12-17$ years

14 years or younger

5-14 years, divided

177 (5-14 years), within 6 months of injury

Conclusion

post-concussion. No gender or age differences were found. However, older athletes showed a greater increase in depression at 14 days postinjury. Somatic symptoms of depression were associated with slower reaction at 7 days postconcussion and lower visual memory scores 14 days post-concussion.

Level of severity (moderate or severe) was not related to behavioral or executive functioning outcomes. Overall, results suggested that boys showed significantly and/or marginally significantly higher rate of dysfunction at school, home, and in the community than girls did.

Brain injury was associated with new onset mood and/or anxiety. $11.4 \%$ of orthopedically injured children, $37.5 \%$ of mild TBI children, and $63.2 \%$ of moderate/severe TBI children showed new anxiety disorders. $2.8 \%$ of orthopedically injured children, $21.4 \%$ of mild TBI children, and $15.8 \%$ of severe TBI children showed new mood disorders. Post-injury level of stress and brain injury severity were the strongest predictors of new onset mood and/or anxiety disorders. Gender was not examined as a predictor.

Children in the mild TBI group had an incidence rate of psychiatric illness at $30 \%$, whereas controls had a significantly lower incidence rate of $20 \%$ in the 3 years post-injury. Children without prior history of psychiatric conditions in the year prior to study showed greater risk for psychiatric condition among children who experienced a mild TBI when compared to particularly hyperactivity. Gender not explored.

Novel anxiety disorder occurred in $8.5 \%$ of cases and novel subclinical anxiety disorders occurred in $17 \%$ of cases. $11 \%$ of the mild TBI group developed an anxiety disorder, and $20 \%$ developed a subclinical anxiety disorder. Preinjury anxiety was not associated with anxiety outcomes in either group. No gender differences were observed. Younger children are at greatest risk for definite anxiety disorder after TBI. There was a trend for concurrent novel depressive disorder to co-occur with novel anxiety disorder.

Novel depressive disorders occurred in $11 \%$ of cases of which $60 \%$ had subclinical nonanxious depression and $40 \%$ had novel subclinical anxious-depression. Injury severity did not differentiate those with and without novel definite/subclinical depression. Gender did not differentiate those with and without novel definite/ subclinical depressive disorder. Increased age was associated with depression and nonanxious depression but not subclinical anxious-depression.

2 years post-injury, novel psychiatric disorder was found in $63 \%$ of children who experienced severe TBI, $21 \%$ of children with mild TBI, and $4 \%$ of children with orthopedic injury only. The severe TBI group also showed greater effect sizes for internalizing symptoms. Gender was not examined due to gender-matched design.

$5-14$ years of age

Personality changes occurred in $13 \%$ of children at 6-12 months post-injury with $12 \%$ continuing in the second year after injury. TBI severity predicted personality change, as did psychosocial adversity at 6-12 months post-injury and adaptive behaviors at 12-24 months post-injury. Gender, age, and 
Table 1 (continued)

\begin{tabular}{llc}
\hline Author & Gender & Age \\
\hline Max et al. (1999) & 24 children per condition (75\% males) & $\begin{array}{c}5-14 \text { years (mild, severe TBI } \\
\text { groups and OI group) }\end{array}$
\end{tabular}

Conclusion

Max et al. (1997)

42 participants mild/moderate to severe TBI (61.9 \% male)

Max et al. (1997)

Nance, Polk-Williams, 116 children were followed for 2 years Collins, and Wiebe (2009)

Peterson et al. (2013)

Schmidt et al. (2010)

Schmidt et al. (2012)

Schwartz et al. (2003)

Sroufe et al. (2010)

Tsai et al. (2014)
132 children (86 males), complicated mild to severe TBI (GCS $<13$ or $\mathrm{CT} / \mathrm{MRI}$ imaging disturbance)
37 children and adolescents with history of mild/moderate and severe TBI (62.2\% males)

6-14 years

11-17 years

12 to 17 years

$7-17$ years 44 children (69 with orthopedic injury and 75 children with moderate to severe TBI; $72 \%$ male).

46 males and 25 females TBI group; orthopedic group $n=64$

Severe TBI ( $n=42 ; 79 \%$ males), moderate TBI ( $n=42,69 \%$ males), and orthopedic injury ( $n=50,60 \%$ males) groups
SES did not predict personality change across either time point.

Severe TBI was associated with decrements in intellectual and memory functions as compared to mild TBI and orthopedic injury. Neuropsychiatric factors (including TBI severity and psychiatric disorders) and a psychosocial disadvantage factor were associated to cognitive outcomes. Gender was not explored due to age-matched nature of design.

Children's severity of injury, preinjury family function, and preinjury lifetime psychiatric history was found to lead to higher risk for novel onset of psychiatric disorders 2 years after injury. Age and gender were not associated with onset of novel psychiatric disorder.

Increased severity of injury, lifetime psychiatric disorder, family psychiatric history, family dysfunction, and lower SES/preinjury intellect predicted onset of novel psychiatric syndromes at 3 months post-injury. Gender, age, seizures, medication, and litigation did not predict novel psychiatric syndromes.

At baseline, deficits in verbal memory, visual memory, visual motor, and reaction time were found in $83.4 \%$ of the sample. Of those tested at the time of follow up $(n=63)$, improvement was found across all subtests, as well as improvement in symptoms. Gender was not investigated.

The sample scored below normative means on tasks of memory and processing speed. Both mother and father reports suggested clinically significant internalizing symptoms at a rate of approximately 2-3 times the general population. Only maternal psychiatric symptoms and female gender were found to show increased risk for internalizing symptoms in teenagers. Paternal psychiatric history predicted risk for internalizing behaviors. Severity did not impact outcomes.

The TBI group showed difficulties with emotional prosody and facial emotions as compared to children who experienced orthopedic injury. Females performed better and improved faster on face emotion recognition tasks.

7-17 years at the time of injury.

Overall, the orthopedic injury group tended to show better decision making than the TBI group. Decision making tended to improve more slowly in females than in males across groups.

Behavioral problems were more pronounced in moderate or severe TBI groups. At the time of extended follow up, $36 \%$ of the severe TBI group, $22 \%$ of the moderate TBI group, and $10 \%$ of the orthopedically injured group showed behavior problems. SES, severity of TBI, and preinjury behavior problems predicted behavioral problems, while working memory, adaptive, and family difficulties tended to co-occur with behavior problems. Gender differences were only found at 6-month follow up, such that boys displayed greater behavior problems

Mild TBI group reported more post-concussive symptoms across baseline, 1 week, and 4-5-week follow ups that the control group. Post-concussive symptoms decrease between 1 and 4-5-week follow-ups. Trailmaking Test Part B differentiated groups. Gender not explored. 
Table 1 (continued)

\begin{tabular}{|c|c|c|c|}
\hline Author & Gender & Age & Conclusion \\
\hline & $\begin{array}{l}\text { Male and females; } \mathrm{TBI}=15,203 \text { and } \\
\text { randomly selected control group } \\
(n=76,015)\end{array}$ & & $\begin{array}{l}\text { TBI resulted in a } 2 \text {-fold increase risk for mood } \\
\text { disorder within } 5 \text { years. Age moderated this effect } \\
\text { such that males were at highest risk at ages } 15-19 \\
\text { and females were at highest risk at } 20-24 \text { years of } \\
\text { age.TBI without hospitalization was associated } \\
\text { with a higher risk for mood disorder as compared } \\
\text { to TBI with hospitalization. }\end{array}$ \\
\hline $\begin{array}{l}\text { Yeates et al. } \\
\qquad(2012)\end{array}$ & $\begin{array}{l}186 \text { mild TBI; } 99 \text { OI; Male }=64 \% \\
\text { of sample }\end{array}$ & $8-15$ years of age & $\begin{array}{l}\text { Children with mild TBI showed greater increases in } \\
\text { cognitive and somatic symptoms. Somatic } \\
\text { symptoms declined over time although cognitive } \\
\text { symptoms persisted } 12 \text { months post-injury. } \\
\text { Increases in symptoms were associated with } \\
\text { declines in health-related quality of life (assessed } \\
\text { at } 3 \text { and } 12 \text { months post-injury) and increased } \\
\text { educational intervention (assessed at initial and } \\
12 \text { month post-injury). Gender was not explored. }\end{array}$ \\
\hline
\end{tabular}

dysfunction at school and home with externalizing behaviors compared to females (Kurowski et al. 2013; Schwartz et al. 2003), with one study finding males to report more sadness than females (Covassin et al. 2007). Males were also found to experience more difficulty with emotional recognition tasks and a slower recovery time compared to females (Schmidt et al. 2010). One study found that the susceptibility for mood disorders differs between the genders based on age. Males aged 15-19 years were found to be most susceptible for the development of a mood disorder, whereas females appeared most susceptible between the ages of 20-24 (Tsai et al. 2014). It is not clear why this difference in susceptibility is present. It may be related to changing expectations for differing ages or the longer term difficulty found after supposed recovery should have occurred particularly for females.

Of the remaining studies that did explore gender, no differences were found in internalizing symptoms (e.g., Chrisman and Richardson 2014; Kontos et al. 2012; Max et al. 1997, 2011, 2012). One study did not suggest differences in personality change (e.g., (Max et al. 2006). Measures of neuropsychological functioning were either not reported in these studies, used only one measure, or were not examined. One study found that age, but not gender, predicted anxiety disorder with younger children at higher risk for developing an anxiety disorder following TBI (Max et al. 2011). An earlier study by this group found that family dysfunction and lower socioeconomic status or lower intellectual ability were more predictive of psychiatric problems following concussion with gender, age, seizures, medication, and litigation status not predictive of psychiatric diagnoses (Max et al. 2012; Max et al. 2006; Max et al. 1997). A further study by this group did not find gender or age to be related to the expression of depressive symptoms in children aged 5 to 14 years following moderate to severe concussions (Max et al. 2012).

Generally, internalizing difficulties such as anxiety and depression were found for both genders in a few studies (Max et al. 2011; Max et al. 2012; Tsai et al. 2014). In contrast, another study found that females were more likely to show impaired visual memory with greater declines in testing performance over time and more self-reported psychological symptoms (Grady 2010; Peterson et al. 2013). Others have found females to have more frequent somatic complaints such as headaches (Toledo et al. 2012) and to show a slower rate of recovery for decision making (Schmidt et al. 2012). As Table 1 indicates, age was also predictive of depression and anxiety with one study finding that younger children were at greatest risk for anxiety disorder compared to older children, while depression was more pronounced in older children/ adolescents (Kontos et al. 2012; Max et al. 2011).

One aspect that has not been extensively studied is whether female athletes are more prone to reporting symptoms than males are. A review of studies looking at baseline and after a sports-related concussion found that females were slightly more likely to report individual symptoms of vision/hearing problems, headaches/migraine, concentration problems, sleep disturbance, and emotional disturbance at baseline (Brown et al. 2015). Post-concussion, females reported less confusion than males. A statistical comparison found females showed higher total symptoms compared to males at both baseline and postconcussion. An interesting finding was that these differences were not found to be significant once a standard mean difference was obtained and appear to be related to normal hormonal changes associated with the menstrual cycle. The symptoms most affected included headache, difficulty concentrating, emotional symptoms, and sleep disturbances that are often also found associated with premenstrual syndrome (Schmelzer et al. 2014). Thus, it was concluded that the differences at baseline and post-concussion may be affected by physiological differences between the genders. Future studies are needed to determine whether these conclusions hold up over time.

A further review of what prompts athletes to report symptoms concluded that it continues to be unclear what factors 
relate to reporting of concussive symptoms (Kay et al. 2015). This review found that two of the five studies reviewed showed that fewer than half of all concussive events were reported. In addition, two of the studies found that a coach's attitude affected inattention to reporting of symptoms. Finally, symptom reporting was negatively influenced by a gameversus-practice mentality, the lack of a medical professional present, and a fear of letting the team down. Certainly all of these aspects, gender, age, and who reports the symptoms, are important aspects to attend to in studying concussions particularly in secondary and collegiate athletes.

Neuropsychological Effects The most sensitive neuropsychological domains for concussions and TBI are attention, memory, and processing speed (Semrud-Clikeman and Bledsoe 2011). Problems with information processing, attention, memory, and significant mood disturbance have been found following a concussion (Centers for Disease Control and Prevention 2014a, 2014b; Felmingham et al. 2004; National Institute of Neurological Disorders and Stroke 2002). Children with concussions which are not substantially interfering with learning may need a 504 plan developed upon initial return to school. Some of the areas to be considered are limiting screen time, providing a place to rest if headaches are persistent, and providing a quiet place to take tests.

For concussions, computerized and web-based assessments are often used such as Immediate Measurement of Performance and Cognitive Test (ImPACT) (Maroon et al. 2000), CogSport (Collie et al. 2001), and CRI (Erlanger et al. 2001). Generally, these measures evaluate reaction time, working memory, attention, concentration, and cognitive flexibility. These measures are fairly good at detecting concussions but have lower samples of performance for children under 15 and should not be used as the only measure of functioning particularly for children and adolescents who continue to show significant problems 1 month after the concussion. For children and adolescents who do not show improvement within 1 month, a comprehensive neuropsychological assessment is warranted. Areas to be evaluated include attention, memory (visual and auditory), executive functioning, processing speed, cognitive flexibility, and sensorimotor and fine motor skills. Table 2 lists the measures frequently used for assessment with children and adolescents with concussion and mild TBI.

One of the most important parts of the neuropsychological evaluation is the opportunity to educate the parent and the child/adolescent about concussions. In our clinical practice, many of the athletes are high-achieving individuals for whom sitting out from their sport is difficult at best and depressing at worst. They are also often impatient to return to play and may ignore or minimize continuing problems. In many cases, these athletes become frustrated with the process and often experience emotional upset if they are not improving as quickly as they wish. Discussion of the nature of concussion, as well as assisting in understanding that multiple concussions may worsen the recovery period, is needed. In addition, it is often helpful to discuss the psychological effects further reviewed in the following paragraph of the concussion and refer to therapy as needed.

\section{Promoting Reentry into the School Setting}

For concussions and TBI, returning to school is the ultimate goal. Initially, many children/adolescents with concussions are very light sensitive and require time away from screens as well as darkened rooms. Planning for reentry into school is an important aspect for the successful return. It generally requires support from the neuropsychologist and medical team to assist parents with navigating the school system requirements.

For a child or adolescent to return to school, it is imperative that all systems in the child's life (home, school, medical) be coordinated. In the past, rehabilitation has generally focused on the physical aspects of injury and not the social-emotional behavioral aspects (National Institute of Mental Health 1998). As stated earlier, the majority of children with moderate to severe injuries will require some form of special education or a 504 plan. It is unknown how many patients with concussions require a 504 plan, but in many cases, we recommend that a 504 plan be developed to assist reentry, as well as to promote a successful school adjustment. It is estimated that $70 \%$ of children with severe head injuries and $40 \%$ of those with moderate injuries will require some special education services due to residual disability (Lowther and Mayfield 2004). Moreover, approximately $20 \%$ of children with head injury had special education needs that predated the injury (Arroyos-Jurado et al. 2000). In addition, Corwin et al. (2014) found that $73 \%$ of children required school accommodations, and $61 \%$ of children experienced a decline in grades. These statistics show that children and adolescents with concussions and/or TBI require school accommodations. Thus, a school team, parents, and adolescent should meet prior to reentry to school to ascertain what needs are present as well as what accommodations can be made. In some ways, concussions are a "hidden" disability because the patient often seems quite "normal" and also wants to be back in the mainstream. Some teachers may mistakenly believe the child/adolescent is "faking" or "lazy" when in fact memory, attention, and sensitivity to stimuli continue to interfere with functioning. In these cases, a neuropsychologist can be extremely helpful in providing input as to what is appropriate for the student.

Placements during recovery can range from residential treatment, to homebound instruction, to school entry with modified day. For most children, a stepwise transition to school is very helpful beginning with a half day placement with time in school increasing during recovery (Rosen and 
Table 2 Frequently used neuropsychological measures

\begin{tabular}{|c|c|}
\hline General orientation & Acute concussion scale in children \\
\hline Intelligence & Wechsler Intelligence Scale for Children-V (Psychological Corporation 2014) \\
\hline Working memory & $\begin{array}{l}\text { Digits Forward and Backward (WISC-V) } \\
\text { Letter Number Sequencing (WISC-V) } \\
\text { Trailmaking (D-KEFS) (Delis, Kaplan, and Kramer 2001) } \\
\text { Color Word Test (Delis et al. 2001) } \\
\text { Behavior Rating Inventory of Executive Functions (Gioia, Isquith, Guy, and Kenworthy 2000) }\end{array}$ \\
\hline Processing speed & $\begin{array}{l}\text { Coding and Symbol Search (WISC-V) } \\
\text { Variability from the Test of Variables of Attention (Greenberg, Kindschi, and Corman 2000) }\end{array}$ \\
\hline Verbal fluency & $\begin{array}{l}\text { Verbal fluency (D-KEFS) } \\
\text { Word Generation (NEPSY2) (Korkman, Kirk, and Kirk 2007) }\end{array}$ \\
\hline Memory & $\begin{array}{l}\text { California Verbal Learning Test-Children's Version (CVLT-C) (Delis, Kramer, Kaplan, and Ober 2000) } \\
\text { Design Memory, Narative Memory (NEPSY) } \\
\text { Paired Associates, List Learning, Visual Memory (Wechsler Memory Scale; WMS) (Psychological Corporation 2009) } \\
\text { Atlantis and Delayed; Rebus and Delayed (Kaufman Assessment Battery for Children-2) (Kaufman and Kaufman 2004) } \\
\text { Rey-Osterreith Complex Figure }\end{array}$ \\
\hline Visual-motor-spatial & $\begin{array}{l}\text { Rey-Osterreith Complex Figure } \\
\text { Developmental Test of Visual-Motor Integration (Beery, Buktenica, and Beery 2006) } \\
\text { Purdue Pegboard (Reddon, Gill, Gauk, and Maerz 1988) } \\
\text { Hand Movements, Finger Tapping (Kaufman and Kaufman 2004) } \\
\text { Judgment of Line Orientation }\end{array}$ \\
\hline Attention/executive function & $\begin{array}{l}\text { Continuous Performance Measures (i.e., Test of Variables of Attention) (Greenberg et al. 2000) } \\
\text { Tower of Hanoi/London (Culbertson and Zillmer 2000) } \\
\text { Wisconsin Card Sorting Test (Grant and Berg 1993) } \\
\text { BRIEF } \\
\text { Behavior Assessment System for Children-2 (BASC-2) (Reynolds and Kamphaus 2004) }\end{array}$ \\
\hline Behavior/emotion & $\begin{array}{l}\text { BASC-2 } \\
\text { Children Behavior Checklist (Achenbach 2007) } \\
\text { Multidimensional Anxiety Scale (MASC) (March 2012) } \\
\text { Revised Child Manifest Anxiety Scale (RCMAS) (Reynolds and Richmond 2008) } \\
\text { Children's Depression Inventory (CDI) (Kovacs 2010) }\end{array}$ \\
\hline Adaptive behavior & $\begin{array}{l}\text { Vineland Adaptive Behavior Scale-2 (Sparrow, Cicchetti, and Bella 2005) } \\
\text { Adaptive Behavior Assessment System-2 (ABAS-2) (Harrison and Oakland 2003) }\end{array}$ \\
\hline
\end{tabular}

Gerring 1986). There are at least five aspects that are important to consider when determining when and how to reintegrate the child into the school setting. These include (1) ability to attend to classroom instruction, (2) ability to understand and retain information, (3) ability to reason and express ideas, (4) ability to problem-solve, (5) ability to plan and monitor one's own performance, and (6) self-control (Cohen 1996).

It is important to provide early planning among professionals in the school and hospital setting in order to ensure a successful reentry into school (Semrud-Clikeman 2001). The individualized education plan (IEP) was developed for discharge needs to include the levels of performance, goals and objectives (short and long-term), need for related services (occupational therapy, physical therapy, speech and language therapy), the anticipated duration of services, and methods for evaluation of the child's progress. Considerations should include whether a half day of school or full day is appropriate, the medications the child is currently prescribed and their side effects, what therapies are required, and what physical plant accommodations (if any) are needed to be implemented (bathroom grab bars, accommodations for step, light sensitivity).

An area that is frequently overlooked includes evaluation of the child's emotional and behavioral functioning. As has been discussed earlier in this article, emotional and behavioral factors are often present. Particular difficulty is often seen with internalizing disorder particularly in females. These internalizing disorders (i.e., depression, anxiety) may not be readily apparent to the teacher particularly in high school where the teacher interacts with the adolescent on a fairly circumscribed basis. Thus, it is important to include the guidance counselor, as well as the school psychologist, in developing the plan to assist in the transition. The pediatric neuropsychologist can be an invaluable addition to this type of planning. It is particularly crucial that a plan be made to provide for additional communications among the team members and possibly with hospital staff. As mentioned earlier, serial evaluations of the child/ adolescent's progress is preferred. Communication of these findings between clinic and school is important and necessary. 
Systems Issues in School Reentry One of the main predictors for good outcome from TBI and concussion is the recognition of possible difficulties in the system that may impede the child's progress (Ylvisaker et al. 2007). Teacher flexibility in accommodating the patient's needs, how often the teacher interacts with the child/adolescent, and quality and quantity of peer interactions have been found to be predictors of successful reintegration (Semrud-Clikeman et al. 2005). Classroom environments that have been found to promote reintegration include structured learning environments, teacher-led instruction rather than independent learning, and the use of classroom materials when related services (OT, PT, speech/language) are being provided (Semrud-Clikeman and Ellison 2009).

\section{Conclusion}

In conclusion, it is apparent that there is much work to be done in understanding concussions, particularly in the case of mild TBI. Many children will seem fully recovered, but neuropsychological assessment may reveal subtle deficits in attention, working memory, and planning that need to be addressed in school programming and in school reentry. In addition, males and females may adjust differently to the residual difficulties found after a concussion. Generally, males tend to act out while females tend to internalize their feelings. In addition, families who have significant dysfunction and poorer socioeconomic status and cognitive ability have also been found to interact with level of improvement following a concussion or a TBI. Assisting these families in adjusting to these difficulties is an important task for a pediatric neuropsychologist or psychologist who is providing assessment services. Schools also need to be cognizant of these factors in expectations of how these children may improve over time and what services may be needed. In addition, children who had premorbid conditions (i.e., ADHD, depression, anxiety) are at higher risk for continuing to experience these difficulties or for these behaviors to be exacerbated by the injury. While these children/ adolescents may appear to be "normal", it is important to educate teachers and support staff as to expression of that, while these difficulties may be subtle, they are disruptive to the child's educational and social/emotional progress. Inservices to teachers and school personnel are an important way to assist school professionals in understanding what concussions are, how the symptoms are manifested, and what recovery may look like. Recognizing internalizing disorders in females and males is an important task for clinical and school professionals alike.

Conflicts of Interest Dr. Semrud-Clikeman and Dr. Klipfel declare that they have no conflict of interest. No animal or human studies were carried out by the authors for this article.

\section{References}

Achenbach, T. M. (2007). Achenbach system of empirically based assessment. Burlington, VT: T. M. Acenbach.

Agel, J., Evans, T. A., Dick, R., Putukian, M., \& Marshall, S. W. (2007). Descriptive epidemiology of collegiate men's soccer injuries: national collegiate athletic associate injury surveillance system, 1988-1989 through 2002-2003. Journal of Athletic Training, 42, 270-277.

Armstrong, C. M., Allen, D. N., Donohue, B. C., \& Mayfield, J. (2008). Sensitivity of the comprehensive trail making test to traumatic brain injury in adolescents. Archives of Clinical Neuropsychology, 23, 351-358.

Arroyos-Jurado, E., Paulsen, J. S., Merrell, K. W., Lindgren, S. D., \& Max, J. E. (2000). Traumatic brain injury in school-age children academic and social outcome. Journal of School Psychology, 38, 571-587.

Baron, I. S. (2008). Maturation into impairment: the merit of delayed settlement of pediatric forensic neuropsychology cases. In R. L. Heilbronner (Ed.), Neuropsychology in the courtroom: expert analysis of reports and testimony (pp. 66-78). New York: Guilford Press.

Beery, K. E., Buktenica, N. A., \& Beery, N. A. (2006). Developmental test of visual-motor integration-5. San Antonio: Pearson.

Broshek, D. K., Kaushik, T., Freeman, J. R., Erlanger, D., Webbe, F. M., \& Barth, J. T. (2005). Sex differences in outcome following sportsrelated concussion. Journal of Neurosurgery, 105, 856-863.

Broshek, D. K., Kaushik, T., Freeman, J. R., Erlanger, D., Webbe, F., \& Barth, J. T. (2012). Sex differences in outcome following sportsrelated concussion. Journal of Neurosurgery, 116, 856-863.

Brown, D. A., Elsass, J. A., Miller, A. J., Reed, L. E., \& Reneker, J. C. (2015). Differences in symptom reporting between males and females at baseline and after a sports-related concussion: a systematic review and meta-analysis. Sports Medicine, 45, 1027-1040.

Centers for Disease Control and Prevention. (2014a). Injury prevention and control: traumatic brain injury. Rates of TBI-related emergency department visits. http://www.cdc.gov/traumaticbraininjury/data/ rates.html.

Centers for Disease Control and Prevention. (2014b). Injury prevention and control: traumatic brain injury. Rates of TBI-related emergency department visits by age group. http://www.cdc.gov/ traumaticbraininjury/data/rates ed byage.html.

Chrisman, P. D., \& Richardson, L. P. (2014). Prevalence of diagnosed depression in adolescents with history of concussion. Journal of Adolescent Health, 54, 582-586.

Cohen, S. B. (1996). Practical guidelines for teachers. In A. L. Goldberg (Ed.), Acquired brain injury in childhood and adolescence: a team and family guide to educational program development and implementation (pp. 126-170). Springfield: Charles C. Thomas.

Collie, A., Darby, D. G., \& Maruff, P. (2001). Computerized cognitive assessment of athletes with sports-related injury. British Journal of Sports Medicine, 35, 297-302.

Collins, M. W., Lowell, M. R., Iverson, G. L., Cantu, T. C., Maroon, J. C., $\&$ Field, M. (2002). Cumulative effects of concussion in high school athletes. Neurosurgery, 58, 275-286.

Collins, M. W., Iverson, G. L., Lovell, M. R., McKeag, D. B., Norwig, J., \& Maroon, J. C. (2003). On-field predictors of neuropsychological and symptom deficit following sports-related concussion. Clinical Journal of Sport Medicine, 13, 222-229.

Colvin, A. C., Mullen, J., Lovell, M. R., West, R. V., Collins, M. W., \& Groh, M. (2009). The role of concussion history and gender in recovery from soccer-related concussion. The American Journal of Sports Medicine, 37, 1699-1704.

Conn, J. M., Annest, J. L., \& Gilchrist, J. (2003). Sports and recreation related injury episodes in the US population: 1997-1999. Injury Prevention, 9, 117-123. 
Corwin, D. J., Zonfrillo, M. R., Master, C. L., Arbogast, K. B., Grady, M. F., Robinson, R. L., et al. (2014). Characteristics of prolonged concussion recovery in a pediatric subspecialty referral population. The Journal of Pediatrics, 165, 1207-1215.

Covassin, T., Schatz, P., \& Swanik, C. B. (2007). Sex differences in neuropsychological function and post-concussion symptoms of concussed collegiate athletes. Neurosurgery, 61, 345-350.

Culbertson, W. C., \& Zillmer, E. A. (2000). Tower of London-Drexel University. Chicago, IL: Multi-Health Systems Inc.

Delaney, S., Lacroix, V. J., Leclerc, S., \& Johnston, K. M. (2002). Concussions among university football and soccer players. Clinical Journal of Sport Medicine, 12, 331-338.

Delis, D. C., Kramer, J. H., Kaplan, E., \& Ober, B. (2000). California verbal learning test, adult version (second ed). San Antonio: The Psychological Corporation.

Delis, D. C., Kaplan, E., \& Kramer, J. H. (2001). Delis-Kaplan executive functioning system: examiner's manual. San Antonio, TX: The Psychological Corporation.

Dick, R. W. (2009). Is there a gender difference in concussion incidence and outcomes? British Journal of Sports Medicine, 43(Suppl 1), i46-i50.

Dick, R. W., Putukian, M., Agel, J., Evans, T. A., \& Marshall, S. W. (2007). Descriptive epidemiology of collegiate women's soccer injuries: national collegiate athletic association injury surveillance system, 1988-1989 through 2002-2003. Journal of Athletic Training, 42, 278-285.

Erlanger, D. M., Saliba, E., Barth, J. T., Almquist, J., Webright, W., \& Freeman, J. R. (2001). Monitoring resolution of postconcussion symptoms in athletes: preliminary results of a web-based neuropsychological test protocol. Journal of Athletic Training, 36, 280-287.

Ewing-Cobbs, L., Barnes, M., Fletcher, J. M., Levin, H. S., Swank, P. R., \& Song, J. (2004). Modeling of longitudinal academic achievement scores after pediatric traumatic brain injury. Developmental Neuropsychology, 25, 107-133.

Farace, E., \& Alves, W. M. (2000). Do women fare worse: a metaanalysis of gender differences in traumatic brain injury. Journal of Neurosurgery, 93, 539-545.

Felmingham, K. L., Baguley, I. J., \& Green, A. J. (2004). Effects of diffuse axonal injury on speed of information processing following severe traumatic brain injury. Neuropsychology, 19, 105-118.

Fineman, I., Giza, C. C., Nahed, B., Lee, S., \& Hovda, D. A. (2000). Inhibition of neocortical plasticity during development by a moderate concussive brain injury. Journal of Neurotrauma, 17, 739-749.

Gioia, G. A., Isquith, P. K., Guy, K., \& Kenworthy, L. (2000). Behavior rating inventory of executive function. Lutz, FL: Psychological Assessment Resources, Inc.

Giza, C. C., \& Hovda, D. A. (2001). The neurometabolic cascade of concussion. Journal of Athletic Trainers, 36, 228-235.

Grady, M. F. (2010). Concussion in the adolescent athlete. Current problems in pediatric and adolescent health care, 40, 154-169.

Grant, D. A., \& Berg, E. A. (1993). Wisconsin card sorting test. Austin, TX: Psychological Corporation, Inc.

Greenberg, L. M., Kindschi, C. L., \& Corman, C. M. (2000). Test of variables of attention: clinical guide. Los Alamitos, CA: Uiversal Attention Disorders.

Guskiewicz, K. M., McCrea, M. A., Marshall, S. W., Cantu, R. C., Randolph, C., Barr, W. B., et al. (2003). Cumulative effects associated with recurrent concussion in collegiate football players. Journal of American Medical Association, 290, 2549-2555.

Hale, J. B., Semrud-Clikeman, M., \& Fiorello, C. A. (2015). School neuropsychology. New York: Guilford Press.

Harrison, P., \& Oakland, T. (2003). Adaptive behavior assessment system-2. San Antonio, TX: Pearson.

Henry, P. C., Hauber, R. P., \& Rice, M. (1992). Factors associated with closed head injury in a pediatric population. Journal of Neuroscience Nursing, 24, 311-316.
Hoffman, J. M., Lucas, S., Dikmen, S., Brunner, R., Diaz-Arrastia, R., Walker, W. C., ... Bell, K. R. (2011). Natural history of headache after traumatic brain injury. Journal of Neurotrauma, $28,1719-1725$.

Jennett, B., \& Teasdale, G. (1981). Management of head injuries. Philadelphia: Davis.

Kaufman, A. S., \& Kaufman, N. L. (2004). Kaufman assessment battery for children-2. Circle Pines, Mn: American Guidance Service.

Kay, M. C., Welch, C. E., \& Valovich McLeod, T. C. (2015). Positive and negative factors that influence concussion reporting among secondary-school athletes. Journal of Sport Rehabiitation, 24, 210-213.

Kontos, A. P., Covassin, T., Elbin, R. J., \& Parker, T. (2012). Depression and neurocognitive performance after concussion among male and female high school and collegiate athletes. Archives of Physical Medicine and Rehabilitation, 93, 1751-1756.

Korkman, M., Kirk, S., \& Kirk, U. (2007). NEPSY II. San Antonio: Pearson.

Kovacs, M. (2010). Children's depression inventory-2. North Tanawada, New York: Multi-Health Systems, Inc.

Kurowski, B. G., Wade, S. L., Kirkwood, M. W., Brown, T. M., Stancin, T., Cassedy, A., \& Taylor, H. G. (2013). Association of parent ratings of executive function with global- and setting-specific behavioral impairment after adolescent traumatic brain injury. Archives of Physical Medicine and Rehabilitation, 94, 543-550.

Lau, B. C., Kontos, A. P., Collins, M. W., Mucha, A., \& Lovell, M. R. (2011). Which on-field signs/symptoms predict protracted recovery from sport-related concussion among high school football players? The American Journal of Sports Medicine, 39, 2311-2318.

Lenroot, R. K., Gogtay, N., Greenstein, D. K., Wells, E. M., Wallace, G. L., Clasen, L. S., et al. (2007). Sexual dimorphism of brain developmental trajectories during childhood and adolescence. NeuroImage, 36, 1065-1073.

Lovell, M. R., Collins, M. W., \& Bradley, J. (2004). Return to play following sports-related concussion. Clinical Sports Medicine, 23, 421-441.

Lowther, J. L., \& Mayfield, J. (2004). Memory functioning in children with traumatic brain injuries: a TOMAL validity study. Archives of Clinical Neuropsychology, 19, 105-118.

Maroon, J. C., Lovell, M. R., Norwig, J., Podell, K., Powell, J. W., \& Hartl, R. (2000). Cerebral concussion in athletes: evaluation and neuropsychological testing. Neurosurgery, 47, 659-672.

Max, J. E., Robin, D. A., Lindgren, S. D., Smith, W. L., Sato, Y., Mattheis, P. J., ... Castillo, C. S. (1997). Traumatic brain injury in children and adolescents: psychiatric disorders at two years. Journal of the American Academy of Child \& Adolescent Psychiatry, 36, 1595-1601.

Max, J. E., Levin, H. S., Schachar, R. J., Landis, R. J., Saunders, A. E., Ewing-Cobbs, L., ... Dennis, M. (2006). Predictors of personality change due to traumatic brain injury in children and adolescents six to twenty-four months after injury. Journal of Neuropsychiatry and Clinical Neurosciences, 18, 21-32.

Max, J. E., Keatley, E., Wilde, E. A., et al. (2011). Anxiety disorders in children and adolescents in the first six months after traumatic brain injury. Journal of Neuropsychiatry and Clinical Neurosciences, 23, 29-39.

Max, J. E., Keatley, E., Wilde, E. A., Bigler, E. D., Schachar, R. J., Saunders, A. E., et al. (2012). Depression in children and adolescents in the first 6 months after traumatic brain injury. International Journal of Developmental Neuroscience, 30, 239-245.

McCrea, M. A., Guskiewicz, K., Randolph, C., Barr, W. B., Hammeke, T. A., Marshal, S. W., ... Kelly, J. P. (2013). Incidence, clinical course, and predictors of prolonged recovery time following sport-related concussion in high school and college athletes. Journal of the International Neuropsychological Society, 19, 22-33. 
McKinlay, A., Ligteringen, V., \& Than, M. (2014). A comparison of concussive symptoms reported by parents for preschool versus school-aged children. Journal of Head Trauma Rehabilitation, 29, 233-238.

Meehan, W. P., Mannix, R. C., Stracciolini, A., Elbin, R. J., \& Collins, M. W. (2013). Symptom severity predicts prolonged recovery after sport-related concussion, but age and amnesia do not. The Journal of Pediatrics, 163, 721-725.

Merritt, V. C., Rabinowitz, A. R., \& Arnett, P. S. (2015). Injury-related predictors of symptom severity following sports-related concussion. Journal of Clinical and Experimental Neuropsychology, 37, 265-275.

Morgan, A. T., Ward, E., Murdoch, B., Kennedy, B., \& Murision, R. (2003). Incidence, characteristics and predictive factors for dysphagia following paediatric traumatic brain injury. Journal of Head Trauma Rehabilitation, 18, 239-251.

National Institute of Mental Health. (1998). Rehabilitation of persons with traumatic brain injury. National Institutes of Health Consensus Statement, 16, 1-41.

National Institute of Neurological Disorders and Stroke. (2002). Traumatic brain injury: hope through research (Vol. 02-158). Bethseda: NIH.

Peterson, R. L., Kirkwood, M. W., Taylor, H. G., Stancin, T., Brown, T. M., \& Wade, S. L. (2013). Adolescents' internalizing problems following traumatic brain injury are related to parents' psychiatric symptoms. The Journal of Head Trauma Rehabilitation, 23, E1-E12.

Psychological Corporation. (2009). Wechsler intelligence scale for children III. San Antonio, TX: Pearson Assessments.

Psychological Corporation. (2014). Wechsler intelligence scale for children-fifth edition. San Antonio, TX: Pearson.

Reddon, J. R., Gill, D. M., Gauk, S. E., \& Maerz, M. D. (1988). Purdue pegboard: test-retest estimates. Perceptual and Motor Skills, 66, 503-506.

Reeves, T. M., Phillips, L. L., \& Povlishock, J. T. (2005). Myelinated and unmyelinated axons of the corpus callosum differ in vulnerability and functional recovery following traumatic brain injury. Experimental Neurology, 196, 126-137.

Reynolds, C. R., \& Kamphaus, R. W. (2004). Behavior assessment system for children-2. Circle Pines, MN: Pearson Assessments.

Reynolds, C. R., \& Richmond, B. O. (2008). Revised children's manifest anxiety scale-2. Torrance, CA: Western Psychological Services.

Rosen, C. D., \& Gerring, J. P. (1986). Head trauma educational reintegration. San Diego: College-Hill Press.

Schmelzer, K., Ditzen, B., \& Weisec, C. (2014). Clinical profiles of premenstrual experiences among women having premenstrual syndrome (PMS): affective changes predominate and relate to social and occupational functioning. Health Care Women International, 1(1-20).

Schmidt, A. T., Hanten, G. R., Li, X., Orsten, K. D., \& Levin, H. S. (2010). Emotion recognition following pediatric traumatic brain injury: longitudinal analysis of emotional prosody and facial emotion recognition. Neuropsychologia, 48, 2869-2877.

Schmidt, A. T., Hanten, G. R., Li, X., Vasquez, A. C., Wilde, E. A., Chapman, S., \& Levin, H. S. (2012). Decision making after pediatric traumatic brain injury: trajectory of recovery and relationship to age and gender. International Journal of Developmental Neuroscience, $30,225-230$.

Schwartz, L., Taylor, H. G., Drotar, D., Yeates, K. O., Wade, S. L., \& Stancin, T. (2003). Long-term behavior problems following pediatric traumatic brain injury: prevalence, predictors, and correlates. Journal of Pediatric Psychology, 28, 251-263.

Semrud-Clikeman, M. (2001). Traumatic brain injury in children and adolescents. New York: Guilford Press.

Semrud-Clikeman, M., \& Bledsoe, J. (2011). Traumatic brain injury in children and adolescents. In A. Davis (Ed.), Handbook of Pediatric Neuropsychology (pp. 963-978). New York: Springer.

Semrud-Clikeman, M., \& Ellison, P. A. T. (2009). Child neuropsychology: assessment and intervention. New York: Springer.

Semrud-Clikeman, M., Kutz, A., \& Strassner, E. (2005). Providing neuropsychological services to learners with traumatic brain injuries. In R. C. D'Amato, E. Fletcher-Janzen, \& C. R. Reynolds (Eds.), Handbook of school neuropsychology (pp. 425-443). Hoboken: Wiley.

Shuttleworth-Edwards, A. B. (2008). Central or peripheral? A positional stance in reaction to the Prague statement on the role of neuropsychological assessment in sports concussion management. Archives of Clinical Neuropsychology, 23, 479-485.

Sieger, A., Goldwater, E., \& Deibert, E. (2015). Does mechanism of injury play a role in recovery from concussion? Journal of Head Trauma Rehabilitation, 30, E52-E56.

Sparrow, S. S., Cicchetti, D., \& Balla, D. (2005). Vineland adaptive behavior scales $(2 \mathrm{ed})$. Minneapolis, MN: Pearson.

Toledo, E., Lebel, A., Becerra, L., Minster, A., Linnmann, C., Maleki, N., ... Borsook, D. (2012). The young brain and concussion: Imaging as a biomarker for diagnosis and prognosis. Neuroscience and Biobehavioral Reviews, 36, 1510-1531.

Tonks, J., Williams, W. H., Frampton, I., Yates, P., \& Slater, A. (2007). Reading emotions after child brain injury: a comparison between children with brain injury and non-injured controls. Brain Injury, 21, 731-739.

Tsai, M. C., Tsai, K. J., Wang, H. K., Sung, P. S., Wu, M. H., Hung, K. W., $\&$ Lin, S. H. (2014). Mood disorders after traumatic brain injury in adolescents and young adults: a nationwide population-based cohort study. The Journal of Pediatrics, 164, 136-141.

U.S. Consumer Product Safety Commission. (2007). National electronic injury surveillance system (NEISS) on-line. Retrieved April 27, 2015 http://www.cpsc.gov/en/Research-Statistics/NEISS-InjuryData/.

Webb, F. M., \& Salinas, C. M. (2011). Sport neuropsychology for children. In A. Davis (Ed.), Handbook of pediatric neuropsychology (pp. 1095-1109). New York: Springer.

Williams, R. M., Puetz, T. W., Giza, C. C., \& Broglio, S. P. (2015). Concussion recovery time among high school and collegiate athletes: a systematic review and meta-analysis. Sports Medicine, 45, 893-903.

Ylvisaker, M., Turkstra, L., Coelho, C. A., Yorkston, K., Kennedy, M., Sohlberg, M. M., \& Avery, J. (2007). Behavioural interventions for children and adults with behaviour disorders after TBI: a systematic review of the evidence. Brain Injury, 21, 769-805. 